\section{A Master Gardener Survey: Promoting Pollinator-friendly Plants Through Education and Outreach}

\author{
Heather Kalaman ${ }^{1}$, Gary W. Knox ${ }^{2}$, Sandra B. Wilson ${ }^{1}$, \\ and Wendy Wilber ${ }^{3}$
}

AdDITIONAL INDEX wORDs. Florida gardening, insect identification, native bees, plant identification, pollinator conservation

Summary. As land-use patterns change over time, some pollinating insects continue to decline both in abundance and diversity. This is due, in part, to reductions in floral resources that provide sufficient nectar and pollen. Our overall goal is to help increase the use of plants that enhance pollinator health by providing research-based information that is easily accessible to the public. To assess the most successful mode of sharing this information, a survey was distributed to more than 4000 Master Gardener (MG) volunteers of Florida. The objectives of our survey were to gauge both knowledge and interest in common pollinators, common pollinator-friendly floral resources, and a favored means of accessing material about additional pollinatorfriendly plants for landscape use. With a response rate of just over $18 \%$, results showed that there is a clear interest among Florida MGs in learning more about pollinators and pollinator-friendly plants with face-to-face classes followed by a website as the preferred modes of accessing educational materials on this topic. Respondents on average were extremely interested in learning more about pollinator plants [mean of 4.41 out of $5.0(S D=0.89)$ ], with greatest interest in butterflies/moths (Lepidoptera), followed by bees (Hymenoptera), birds (Aves), bats (Chiroptera), and beetles (Coleoptera). Overall, MG participants felt more confident $(P<0.0001)$ in their knowledge of pollinator-friendly plants (mean 3.24 out of 5.0) than pollinator insects (mean 3.01 out of 5.0). When tested, $88.5 \%$ were able to correctly identify black-eyed susan (Rudbeckia hirta), with $70.1 \%$ correctly identifying spotted beebalm (Monarda punctata). Variations were observed in tested knowledge of pollinating insects, with $90.2 \%$ correctly identifying a zebra longwing (Heliconius charithonia) and only $32.6 \%$ correctly identifying a stripedsweat bee (Agapostemon splendens). These results revealed that MGs perceived themselves to be fairly knowledgeable about both pollinator plants and pollinating insects, yet their tested knowledge ranged widely depending on the actual plant and pollinator type. This suggests an emphasis be given for future MG training focused on diverse plant and pollinator species, preferably in a face-to-face environment. Results also show that additional resources regarding pollinator-friendly plants, as well as identification material on pollinating insects, are both desired and valued by our Florida MG community.

$\mathrm{T}$ The significant contributions made by pollinating insects to the prosperity and health of our many ecosystems are well known among both the public and the scientific community (Novacek, 2008; Smith, 2016). Not only are the pollination services provided by these insects fundamental for the proliferation of some of our most prized cultivated crops, but nearly $90 \%$ of all wild plants depend on insects to survive and flourish (Ashman et al., 2004; Hoshiba and Sasaki, 2008). Nonetheless, as our land-use patterns have been altered over time, some pollinating insects have continued to decline both in abundance and diversity due, in part, to reductions in floral resources that provide sufficient nectar and pollen
(Foley et al., 2005). One possible way to help mitigate these threats is to increase the use of plants that enhance pollinator health by generating research-based information that is easily attainable by the public. In a recent survey, $46 \%$ of consumers purchased pollinator-friendly plants for their home landscape, noting their enthusiasm for both aiding in pollinator health and their attractive landscape qualities (Campbell et al., 2017). Information regarding gardening and landscape use plants is available in many formats from phone-based applications, websites, webinars, and face-to-face classes (Varlamoff et al., 2002). Depending on the demographics of the community, various sources are relied on more heavily than others. Earlier studies have shown, for example, that information from Internet sources was less commonly acquired by participants over age 61 years than by younger survey participants. Notably, when these survey participants were asked what the most important attribute was in accessing and retaining gardening information, convenience and interaction ranked the highest (Meyer and Foord, 2008).

Creating opportunities for the public to conveniently access educational materials on pollinators and pollinator-friendly plants with an interactive tone can be accomplished in a variety of ways. Through encouragement and employment of enthusiast community members and apprentice naturalists, enormous strides can be made toward the sustainability of our pollinators. For example, volunteerbased citizen science groups have been invaluable contributors to an array of data scientists rely on every day due to the widespread use of mobile computing, large-scale and free computational power, and the personal satisfaction gained from participating in ongoing research (Bonney et al., 2009; Silvertown, 2009). Remarkably, data collected through an online database for bird observations (eBird; Cornell University, Ithaca, NY) has been used in at least 90 peer-reviewed articles and book chapters on a wide range of ornithological topics (Bonney et al., 2014). Surely, the most effective tool for public acknowledgment and comprehension of scientific information is through cooperation. Therefore, the objectives of our survey were to gauge overall MG desire to learn more about pollinators and pollinator-friendly plants, to assess both perceived and tested knowledge of common pollinators and their associated floral preferences, and to determine the preferred means of accessing educational material about landscape use plants that will aid in supporting our pollinating insect communities.

\section{Materials and methods}

Survey. A survey questionnaire was constructed to anonymously assess the interest and knowledge Florida MGs have related to pollinator plants. The resulting survey (approved by the University of Florida Institutional Review Board, ID number 201802622) comprised 16 questions consisting of free response, 
image-based identification, Likert scale, and multiple choice. Questions focused on 1) gauging overall desire to learn more about pollinators and their preferred floral resources, 2) assessing both perceived and tested knowledge of common pollinators and common pollinator-friendly plants of Florida, and 3 ) ascertaining the preferred means of accessing educational material about floral resources that will aid in supporting pollinating insect communities (Table 1).

Survey Distribution. The survey was designed and implemented using an online software platform (Qualtrics XM; Qualtrics, Provo, UT). This delivery format was employed as online surveys have proven more effective than standard mail surveys due to their affordability, convenience, speed and timeliness (Evans and Mathur, 2005). The survey was distributed by the Florida Statewide MG Volunteer Program Coordinator, using an e-mail list-serve address representing all 4000 registered MGs. MG volunteers were our target audience for this study because they have historically and consistently displayed great interest in growing and learning about landscape-use plants. As a volunteerdriven organization working closely with the University of Florida's Institute of Food and Agricultural Sciences Extension Service (UF/IFAS), they work diligently not only to

Received for publication 17 July 2019. Accepted for publication 17 Dec. 2019.

Published online 24 January 2020.

${ }^{1}$ Institute of Food and Agricultural Sciences Extension Service (IFAS), Department of Environmental Horticulture, University of Florida, P.O. Box 110675, Gainesville, FL 32611

${ }^{2}$ IFAS, Department of Environmental Horticulture, North Florida Research and Education Center, University of Florida, 155 Research Road, Quincy, FL 32351

${ }^{3}$ IFAS, Center for Landscape Conservation and Ecology, University of Florida, P.O. Box 110675, Gainesville, FL 32611

We gratefully acknowledge the U.S. Department of Agriculture, National Institute of Food and Agriculture, Crop Protection and Pest Management Extension Implementation Project for funding this project and James Cooley for statistical consultation of survey results.

This research was presented as a poster and paper proceeding at the Florida State Horticultural Society Annual Meeting, 9-11 June 2019, Orlando, FL.

H.K. is the corresponding author. E-mail: hkalaman@ ufl.edu.

This is an open access article distributed under the CC BY-NC-ND license (https://creativecommons.org/ licenses/by-nc-nd/4.0/).

https://doi.org/10.21273/HORTTECH04460-19

Table 1. Sixteen questions included within the online survey instrument emailed to 4000 Master Gardeners in Florida to gauge both knowledge and interest in common pollinators, common pollinator-friendly floral resources, and a favored means of accessing material about additional pollinator-friendly plants for landscape use.

1. How confident are you in your ability to identify different pollinators? $(0-5$ scale $)$ 2. Do you feel more interested in specific types of pollinators? (choose all that apply)

3 . How familiar are you with pollinator-friendly plants? $(0-5$ scale $)$

4. How interested are you in learning more about pollinator-friendly plants? $(0-5$ scale $)$

5. Do you currently grow any pollinator-friendly plants? (yes or no)

6. How many different species of pollinator-friendly plants do you grow?

(selected category)

7. Do you currently use any nature-oriented phone applications or websites? (yes or no)

8. What, if any, nature-oriented phone applications or websites do you typically use?

(choose all that apply)

9. If you answered "Other," what phone application or website do you commonly use? (open answer)

10. What is it about this phone application or website that you enjoy the most?

(choose all that apply)

11. If you answered "Other," why do you enjoy this phone application or website? (open answer)

12. What would be the most successful mode of learning more about pollinators and pollinator-friendly plants? (open answer)

13. Name this pollinator-friendly plant (image). (multiple choice)

14. Name this pollinator-friendly plant (image). (multiple choice)

15. Name this pollinator (image). (multiple choice)

16. Name this pollinator (image). (multiple choice)

expand their own knowledge of horticulture but also to share that knowledge with their communities. The survey link was accompanied with a letter introducing members of the project, a mission statement, instructions for further survey involvement, and a message of gratitude for participation because studies have shown personalization and salient acknowledgment contribute to better response rates (Schaefer and Dillman, 1998). Individual responses were recorded and remained anonymous throughout the course of survey data collection because assured anonymity tends to lend itself to more sincere or honest answers (Stanton, 1998). To avoid some potential weaknesses of online surveys, such as a respondent's lack of online experience or expertise and technological variations (Evans and Mathur, 2005), the survey remained open for 6 weeks, and all configuration issues and inquiries were answered accordingly.

The mean and standard deviation of survey responses were calculated using Qualtrics XM. When appropriate, means were compared using a paired Wilcoxon signed-rank test implemented in SAS (version 9.2; SAS Institute, Cary, NC) at $P \leq 0.05$.

\section{Results and discussion}

Survey response. The online survey was initiated by 970 participants, with 731 successfully completing all 16 questions ( $18.3 \%$ response rate, $75.4 \%$ completion rate).

OVERALL DESIRE TO LEARN MORE ABOUT POLLINATORS AND POLLINATORS PLANTS. The aim of the first portion of the survey was to assess overall interest in insect and non-insect pollinators, as well as the desire among our MG participants to learn more about pollinator-friendly resources. When asked to select each of the pollinators they felt most interested in [butterflies and moths (Lepidoptera), bees (Hymenoptera), birds (Aves), bats (Chiroptera), and beetles (Coleoptera)], "butterflies and moths" received the greatest number of responses (821), followed by "bees" (729), "birds" (628), "bats" (326), and "beetles" (209) (Fig. 1). Participants were then asked how interested they were in learning more about pollinator-friendly plants for landscape use on a Likert scale ranging from 0 to 5 $(0=$ not at all interested, $5=$ extremely interested). With 797 respondents, results showed a mean of 4.41 out of a possible of $5(\mathrm{SD}=0.89)($ Table 2$)$. Results from this portion of our survey 
indicated that there is a strong desire by MG volunteers to learn more about pollinator-friendly plants, and that of the five pollinator choices listed, MGs are most interested in butterflies/moths and bees. Of interest to note is that $95.4 \%$ reported that they already grow pollinator-friendly plants. When asked how many species they grow, $78.1 \%$ reported growing fewer than 20 species and $21.9 \%$ reported growing more than 20 species (Fig. 2). Studies have shown that an increase in the diversity of floral species planted plays a significant role in both pollinator abundance and diversification, due to prolonged seasonal resource value and availability of a wide range of pollen and nectar sources (Potts et al., 2003; Williams et al., 2015).

PERCEIVED AND TESTED KNOWLEDGE. The second objective of the survey was to gauge MGs perceived knowledge of both common insect pollinators and popular

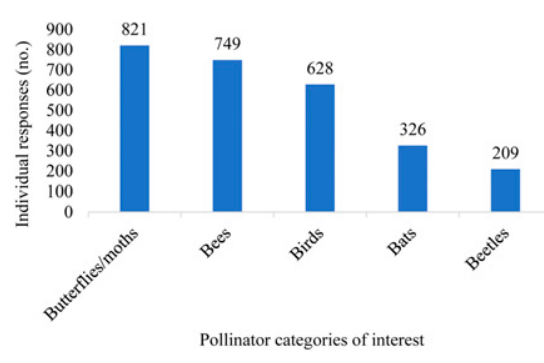

Fig. 1. Individual Florida Master Gardener responses when asked to select each of the pollinators types they felt most interested in from five choices: butterflies/moths, bees, birds, beetles, and bats. pollinator-friendly floral resources and to test that perceived knowledge. When asked how familiar they were with pollinator-friendly plants on a Likert scale from 0 to $5(0=$ not at all knowledgeable, $5=$ extremely knowledgeable), the mean response was 3.29 , showing a slightly above moderate familiarity. When asked how confident they were in their ability to identify different pollinators, the mean was 3.01 (731 respondents), slightly lower than reported for pollinatorfriendly plants (Table 2 ).

When tested on plants and insect pollinators, on average MGs performed higher in their tested knowledge of plants compared with insects (Table 2). For example, when shown a photo of a commonly advertised pollinator plant, spotted beebalm (Monarda punctata), 587 of 838 respondents $(70.1 \%)$ were able to correctly identify an image of this floral resource. Similarly, when shown a photo of a black-eyed susan ( $R u d$ beckia hirta), 744 of 841 respondents $(88.5 \%)$ were able to correctly identify this plant. MGs tested knowledge of two common pollinating insects varied depending on the image provided. When shown an image of the Florida state butterfly, the zebra longwing (Heliconius charithonia), 731 of 833 respondents $(90.2 \%)$ were able to correctly identify it (Table 2 ). Yet when shown an image of a Florida native striped-sweat bee (Agapostemon splendens), 270 of 829 respondents $(32.6 \%)$ were able to correctly identify this bee pollinator.

In addition to providing information on which plants best serve as beneficial floral resources to our

Table 2. Master Gardener participants survey results showing overall interest in learning more about pollinator-friendly plants and their perceived and tested knowledge of identifying pollinators and pollinator-friendly plants. ${ }^{\mathrm{z}}$

\begin{tabular}{|c|c|c|c|}
\hline & $\begin{array}{c}\text { Perceived } \\
\text { knowledge } \\
{[\text { mean } \pm \text { SD }} \\
(0-5 \text { scale })]^{y}\end{array}$ & $\begin{array}{c}\text { Tested } \\
\text { knowledge } \\
{[\text { mean }(\% \text { correct }} \\
\text { response })]^{\mathrm{x}}\end{array}$ & $\begin{array}{l}\text { Interest to } \\
\text { learn more } \\
{[\text { mean } \pm \text { SD }} \\
(0-5 \text { scale })]^{\mathrm{w}} \\
\end{array}$ \\
\hline Pollinator-friendly plants & & & $4.41 \pm 0.89$ \\
\hline Black-eyed susan & & 88.5 & \\
\hline Spotted beebalm & & 70.1 & \\
\hline Pollinators & $3.01 \pm 1.21$ & & \\
\hline Zebra longwing & & 90.2 & \\
\hline Striped-sweat bee & & 32.6 & \\
\hline
\end{tabular}

pollinating insect communities, educational materials to aid in the identification and conservation of our native bees here in the United States is crucial. Growing interest and concern for insect pollinators, particularly bees, is evident through recent studies that have shown that $99 \%$ of surveyed respondents believed bees were critically important in their ecosystem services (Wilson et al., 2017). However, the ability to distinguish bee types is less common. For example, Wilson et al. (2017), found that these same survey respondents were largely only able to successfully identify honeybees (Apis mellifera) and bumble bees (Bombus sp.) compared with other bee species. This is not surprising with recent bee campaigns associated with the extensive losses in honeybee communities due to various pests, pathogens, climatic changes, and other stressors (Pettis and Delaplane, 2010). With more than 4000 currently described species of native bees in North America, Florida is home to more than 300 species, 29 of which are entirely endemic to the state (Michner, 2000; Pascarella et al., 1999). Resources that aid in the identification of native bee communities will help in educating consumers about the diversity of existing bee species.

Preferred mode of Learning. The last portion of our survey was designed to determine the most successful means of both developing and distributing educational materials about pollinating insects and pollinatorfriendly plants for landscape use. When MGs were asked to identify their preferred mode of learning about pollinators and pollinatorfriendly plants, a face-to-face class was preferred $(36.1 \%)$, followed by an online website (21.6\%) (Fig. 3). Preference for a face-to-face class may be influenced by the fact that the median age range of a MG volunteer is 65 and the majority are retired, addressing the possibility of technological apprehension as well as the probable unrestricted free time to dedicate to in-person classes (Dorn et al., 2018; Relf and McDaniel, 1994; Vines et al., 2016). It should be noted that information technology-based training programs still serve as effective educational resources as they have shown to have fewer missed participants, can be more cost effective, and produce similar levels of mastery of material as face-to-face training 
programs (Lim et al., 2007) In fact, when asked whether they currently use any nature-oriented phone applications or websites, 532 of 859 respondents (61.9\%) answered "yes" (data not presented).

When asked to select the natureoriented phone applications or websites they most frequently use from a list of five, respondents most frequently chose Facebook Groups [Facebook, Menlo Park, CA (21\%)], followed by National Audubon Society [Manhattan, NY (18.9\%)], and the phone application PlantNet [Paris, France (10.5\%)] (data not presented). The most common reasons for use of these websites or phone applications were that they were easy to use, free, and interactive. We additionally allowed for an open answer option for this question ("other"), completed by $37.9 \%$ of respondents. It is of interest to note that of these open answer responses, many respondents (44.3\%) answered "UF/IFAS" and/or "EDIS" (Electronic Data

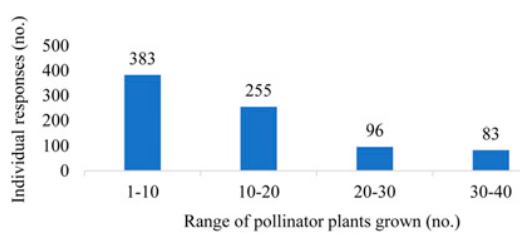

Fig. 2. Individual Florida Master Gardener responses when asked how many pollinator-friendly plants they currently grow in their home garden/ landscape.
Information Sources of UF/IFAS Extension) resources, followed by the phone application PictureThis [Glority, Hangzhou, China (9.8\%)], Florida Native Plant Society [Winter Park, FL (5.7\%)], and the phone application PlantSnap [PlantSnap, Telluride, CO (4.7\%)] (data not presented). Participants stated they use these other resources because they are research based, reviewed by the scientific community, and state specific.

In summary, results from our survey revealed a strong MG interest in learning more about pollinatorfriendly plants, as well as specific types of pollinators. Although a significant number of Florida MG volunteers acknowledged that they already grow several pollinator-friendly plants in their landscape, providing additional research-based materials on pollinator-friendly plants and pollinating insects will allow for both expansion of MG knowledge on this topic and the dispersal of that knowledge to larger audiences with the overall goal of supporting pollinating insect communities. Differences in perceived and tested knowledge of both pollinator-friendly plants and insect pollinators also suggest an emphasis to be given in developing targeted extension programs to meet these needs. By providing additional identification materials to our MG volunteers on important pollinating insects such as Florida native bee communities, we can try to alleviate some of the hardship these organisms face as a result of our changing landscape patterns.

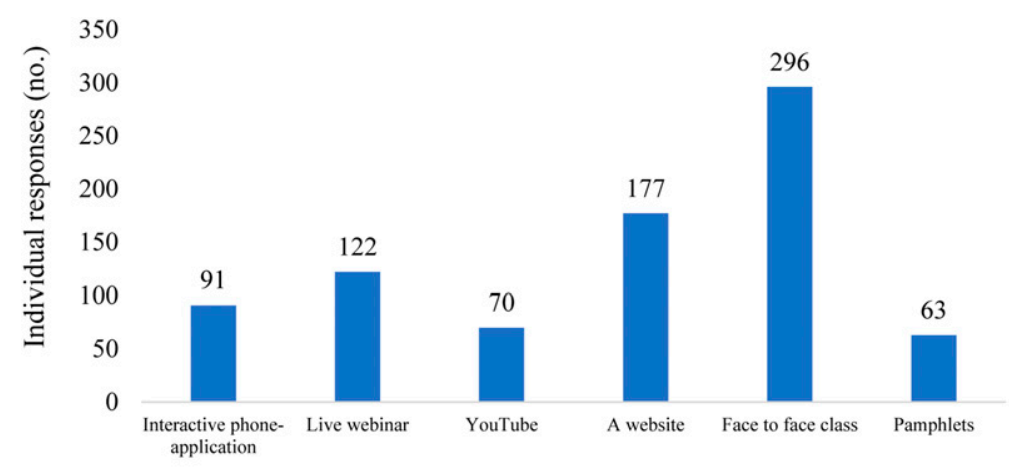

Florida MGs desired mode of learning more about pollinators and pollinatorfriendly plants

Fig. 3. Individual Florida Master Gardener (MG) survey responses when asked their preferred mode of learning more about pollinators and pollinator plants from six choices: interactive phone-application, live webinar, a YouTube video sharing platform (YouTube, San Bruno, CA), a website, face-to-face class, and pamphlets.

\section{Literature cited}

Ashman, T.L., T. Knight, J. Steets, P. Amarasekare, M. Burd, D. Campbell, M. Dudash, M. Johnston, S. Mazer, R. Mitchell, M. Morgan, and W. Wilson. 2004. Pollen limitation of plant reproduction: Ecological and evolutionary causes and consequences. Ecology 85:24092421 .

Bonney, R., C. Cooper, J. Dickinson, S. Kelling, T. Phillips, K. Rosenberg, and J. Shirk. 2009. Citizen science: A developing tool for expanding science knowledge and scientific literacy. Bioscience 59:977984.

Bonney, R., J. Shirk, T. Phillips, A. Wiggins, H. Ballard, A. Miller-Rushing, and J. Parrish. 2014. Next steps for citizen science. Science 342:1436-1437.

Campbell, B., H. Khachatryan, and A. Rihn. 2017. Pollinator-friendly plants: Reasons for and barriers to purchase. HortTechnology 27:831-839.

Dorn, S.T., M.G. Newberry, III, E.M. Bauske, and S.V. Pannisi. 2018. Extension master gardeners of the 21 st century: Educated, prosperous, and committed. HortTechnology 28:218-229.

Evans, J. and A. Mathur. 2005. The value of online surveys. Internet Res. 15:195219.

Foley, J.A., R. DeFries, G. Asner, C. Barford, G. Bonan, S. Carpenter, F.S. Chaplin, M. Coe, G. Daily, H. Gibbs, J. Helkowski, T. Holloway, E. Howard, C. Kucharik, C. Monfreda, J. Patz, C. Prentice, N. Ramankutty, and P. Snyder. 2005. Global consequences of land use. Science 309: $570-574$.

Hoshiba, H. and M. Sasaki. 2008. Perspectives of multi-modal contribution of honeybee resources to our life. Entomol. Res. 38:15-21.

Lim, H., S. Lee, and K. Nam. 2007. Validating e-learning factors affecting training effectiveness. Intl. J. Inf. Mgt. 27:22-35.

Meyer, M. and K. Foord. 2008. Consumer preferences and perceptions of gardening information. HortTechnology 18:162-167.

Michner, C.D. 2000. Bees of the world. 2nd ed. Johns Hopkins Univ. Press, Baltimore, MD.

Novacek, M. 2008. Engaging the public in biodiversity issues. Proc. Natl. Acad. Sci. USA 105:11571-11578.

Pascarella, J., K. Waddington, and P. Neal. 1999. The bee fauna (Hymentoptera: Apoidea) of Everglades National Park, Florida and adjacent areas: Distribution, 
phenology, and biogeography. J. Kans. Entomol. Soc. 72:32-45.

Pettis, J. and K. Delaplane. 2010. Coordinated responses to honeybee decline in the USA. Apidologie 41:256-263.

Potts, S., B. Vulliamy, A. Dafni, G. Ne'eman, and P. Willmer. 2003. Linking bees and flowers: How do floral communities structure pollinator communities. Ecology 84:2628-2642.

Relf, D. and A. McDaniel. 1994. Assessing master gardeners' priorities. HortTechnology 4:181-184.

Schaefer, R. and D.A. Dillman. 1998. Development of a standard email methodology: Results of an experiment. Public Opin. Q. 62:378-397.
Silvertown, J. 2009. A new dawn for citizen science. Trends Ecol. Evol. 24:467471.

Smith, T. 2016. Honeybees: The queens of mass media, despite minority rule among insect pollinators. Insect Conserv. Divers. 9:384-390.

Stanton, J.M. 1998. An empirical assessment of data collection using the internet. Person. Psychol. 51:709-726.

Varlamoff, S., W. Florkowski, J. Latimer, S.K. Braman, and J. Jordan. 2002. Homeowners and their choice of information sources about gardening. J. Ext. 40(3): 3FEA7. 15 May 2019. <https://www.joe. org/joe/2002june/a7.php>.
Vines, K.A., K. Jeannette, E. Eubanks, M. Lawrence, and R. Radharishna. 2016. Extension master gardener social media needs: A national study. J. Ext. 54(2): 2FEA5. 7 Nov 2019. <https://joe.org/ joe/2016april/a5.php>.

Williams, N., K. Ward, N. Pope, R. Isaacs, J. Wilson, E. May, J. Ellis, J. Daniels, A. Pence, K. Ullmann, and J. Peters. 2015. Native wildflower plantings support wild bee abundance and diversity in agricultural landscapes across the United States. Ecol. Appl. 25:2119-2131.

Wilson, J., M. Forister, and O. Carril. 2017. Interest exceeds understanding in public support of bee conservation. Front. Ecol. Environ. 15:460-466. 